\title{
Characterization and Stability Studies on Vegetable Nanoemulsions Obtained by Low Energy Process
}

Monica Maruno*

Department of Pharmaceutical Sciences, Faculty of Pharmaceutical Sciences of Ribeirão Preto, University of São Paulo, Brazil

\begin{abstract}
Background: The use of vegetable oils in the pharmaceutical and cosmetic industry is becoming increasingly attractive worldwide. Native to Cerrado biome of Brazil, we can mention baru seeds, which oil has a high degree of unsaturation. Its major constituents are the fatty acids oleic and linoleic, and, besides that it contains significant amounts of tocopherols and phytosterols. Emulsified systems are the most common form presentation of industrial products. Its excellent ability to solubilize hydrophilic and lipophilic compounds explains its scientific and commercial importance. The design of these systems requires knowledge of the main factors that influence their formation, consequently, stability and performance. The objective of this research was the development and characterization of a nanoemulsion with baru oil using an economic process. The steps involved in the planning process of development of the systems were: 1) choice of emulsification methodology 2) development and characterization of formulations; 3) stability studies.

Results: The use of low energy emulsification methodology so, a low-cost process, allow obtention of stable nanoemulsion having particle size distribution between $100.67 \pm 8.39$ and $111.45 \pm 5.44 \mathrm{~nm}$. The study of the physicochemical properties of the formulations showed no signs of instability of the formulations during the storage period under specific temperature conditions and the nanoemulsion has fine appearance, translucent aspect and bluish reflect, which are in accordance with the concept of nanoemulsions.

Conclusions: The optimization of composition variables to minimize droplet size and polydispersity index allowed the obtention of a stable nanoemulsion by using a classic and low cost methodology. The developed system may be a good alternative delivery system, particularly because the use of vegetable oil follows a global trend of using renewable resources for sustainable development in cosmetic and pharmaceutical industry.
\end{abstract}

Keywords: Baru oil; Nanoemulsion; Stability; Low cost; Cuttingedge system

\section{Background}

Studies carried out by Almeida; Silva and Ribeiro [1] on the productivity of Baru native of the Savana do Brazil biome, revealed great economic and sustainable potential being used regionally in human food for presenting significant amounts of lipids, proteins, fibers and minerals.

Their concentration in phenolic compounds is high when compared to macadamia nuts, Brazil nut, cashew nuts and walnuts. Baru oil is rich in polyunsaturated fatty acids, terpenes (mono and sesquiterpenes) and phytosterols [2,3]. Thus, the chemical composition associated with economic potential stimulates the use of baru oil (D. alata) as raw material for different industries such as food, pharmaceutical and cosmetic [4-7]. Nanodispersed systems are prepared by methods divided into two categories: high or low energy emulsification, depending on the physical parameters involved in the formation of globules [8].

Phase inversion emulsification methods induce the inversion of water-in-oil $(\mathrm{O} / \mathrm{W})$ systems to oil-in-water $(\mathrm{O} / \mathrm{W})$ or vice versa, and the curvature of the $\mathrm{O} / \mathrm{W}$ interface changes gradually. These methods are divided into Phase Inversion Temperature Method (TIF) and Phase Inversion Emulsification (EIF) depending on the phase inversion point and the volumetric ratio between the amounts of the aqueous and oily phases. TIF and EIF are also called Transitional and Catastrophic Phase Inversion, respectively [9].

The principle of Transitional Phase Inversion was introduced by Shinoda and Saito [10] and is based on changes in the properties of surfactants induced by temperature-. Conversely the Catastrophic Phase Inversion (CPI) occurs due to changes in the composition of the formulation (increase in the volumetric ratio of the dispersed phase) during the emulsification process at constant temperature [11-13].

The nanoemulsions present globules in the $50-200 \mathrm{~nm}$ size range and for this reason have a larger contact surface allowing greater wettability, spreadability and penetration of the active substances in the skin, besides providing differentiated sensorial. Macroscopically present as liquid systems of low viscosity and with intense blue reflection [14-16]

Nanoemulsion systems are susceptible to instability process, with being Ostwald ripening more common. The phenomenon of instability of higher occurrence in nanoemulsions is known as Ostwald ripening: a process in which the greater solubility of the dispersed phase in the dispersant, conferred by the greater interfacial curvature of the dispersed globule, allows the larger globules to increase in size to the detriment of the smaller ones causing an increase in the average radius of the nanoemulsion globules $[9,17,18]$.

The objective of this research was to propose an economical method to obtain nanoemulsions using baru oil.

*Corresponding author: Monica Maruno, Department of Pharmaceutical Sciences, Faculty of Pharmaceutical Sciences of Ribeirão Preto, University of São Paulo, Avenida do Café, s/n, Bairro Monte Alegre, Ribeirão Preto, SP, 14040-903, Brazil, Tel: 5516 36024432; E-mail: pedranjo@fcfrp.usp.br

Received September 11, 2017; Accepted November 13, 2017; Published November 20, 2017

Citation: Maruno M (2017) Characterization and Stability Studies on Vegetable Nanoemulsions Obtained by Low Energy Process. J Nanomedic Nanotechnol S8: 003. doi:10.4172/2157-7439.S8-003

Copyright: @ 2017 Maruno M. This is an open-access article distributed unde the terms of the Creative Commons Attribution License, which permits unrestricted use, distribution, and reproduction in any medium, provided the original author and source are credited. 
Citation: Maruno M (2017) Characterization and Stability Studies on Vegetable Nanoemulsions Obtained by Low Energy Process. J Nanomedic Nanotechnol S8: 003. doi:10.4172/2157-7439.S8-003

\section{Methods}

\section{Chemicals}

Croda do Brasil-Sorbitan oleate (HLB value $=4.3$, Polysorbate 80 (HLB value $=15.0$ );

Oxiteno do Brasil-Ceteareth 5 (HLB value $=9.2$; Ceteareth 20 (HLB value $=15.7)$; Steareth -2 (HLB value=4.9), PEG-15 Castor oil (HLB value $=8.3)$ PEG-30 castor oil $(\mathrm{HLB}$ value $=10.8)$ and $\mathrm{PEG}-40$ Castor oil $($ HLB value $=13.0)$.

Lipo do Brasil-Polysorbate 80 HLB value=15.0); ChemyunionDMDM Hydantoin (and) Iodopropynyl Butylcarbamate was employed as preservative.

Purified water obtained by reverse osmosis as aqueous phase.

\section{Emulsification method}

The formulations were developed according to the phase inversion technique where the aqueous phase heated to $75 \pm 2{ }^{\circ} \mathrm{C}$ was added to the oil and surfactant system at the same temperature while maintaining the mechanical stirring (IKA ${ }^{\circledR}$ RW Digital) at controlled speed (600 $\mathrm{rpm})$ until complete cooling $\left(25 \pm 2^{\circ} \mathrm{C}\right)$.

\section{Study of the HLB required value for baru oil}

The pair of surfactants selected for the study of the HLB value was Sorbitan oleate and Polysorbate-80. The study was divided into two stages (step I and step II) (Figure 1).

\section{Choice of surfactant}

Different chemical classes of hydrophilic surfactants and/or lipophilic surfactants in predetermined HLB value were used: Sorbitan oleate and Ceteareth-5; Sorbitan oleate and Ceteareth-20; Steareth-2 and Ceteareth-5; Steareth-2 and Polysorbate-80; Sorbitan oleate and PEG-15 castor oil; Sorbitan oleate and PEG-30 castor oil; Sorbitan oleate and PEG-40 castor oil.

\section{Ternary diagram}

Three different conditions were worked based on ternary diagrams:

- The concentrations of each component being varied by 5.0 at $5.0 \%$ only in the region where the aqueous phase concentration was greater than $75.0 \%$ and the maximum concentration of surfactants $10.0 \%$. Thus ten formulations were obtained using only PEG-15 Castor oil;

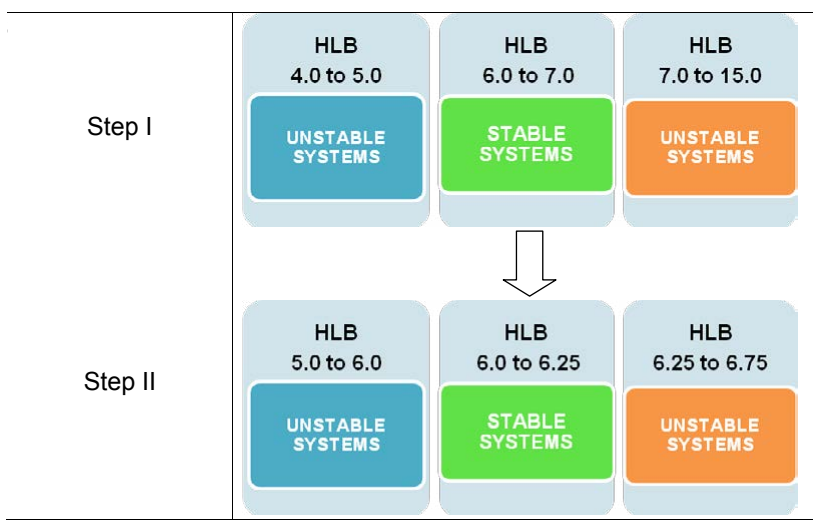

Figure 1: Formulations obtained in the HLB determination test of baru oil.
- The concentrations of each component being varied by 5.0 at $5.0 \%$ only in the region where the aqueous phase concentration was greater than $75.0 \%$ and the maximum concentration of surfactants was $10.0 \%$. Thus, five formulations were obtained using the surfactant pair PEG-15 Castor oil+Sorbitan oleate.

- The concentrations of each component being varied by 2.5 at $2.5 \%$ only in the region where the aqueous phase concentration was greater than $75.0 \%$ and the maximum concentration of surfactants was $10.0 \%$. Thus, five formulations were obtained using the surfactant pair PEG-15 Castor oil+Sorbitan oleate.

\section{Preliminary stability test}

Centrifugation test: Five g of each nanoemulsion were submitted to centrifuge cycles (70 g; $440 \mathrm{~g}$ and $863 \mathrm{~g}$ ) during $15 \mathrm{~min}$ each, at room temperature $\left(25 \pm 5^{\circ} \mathrm{C}\right)$. Only formulations that did not show creaming or phase separation signs $(\mathrm{N}=$ normal or $\mathrm{SL}=$ slightly modified) were considerate stable. The tests were performed in triplicate.

\section{Thermal stress}

The emulsions were subjected to thermal stress in a thermostated bath at a temperature range of $40 \pm 2^{\circ} \mathrm{C}$ to $80 \pm 2^{\circ} \mathrm{C}$, increasing the temperature in $5^{\circ} \mathrm{C}$ steps. The samples were held at each temperature for $30 \mathrm{~min}$ and then evaluated macroscopically. For this test, the following nomenclature was used to classify them: $\mathrm{N}=\mathrm{Normal}$; without change; LM=Slightly Modified; M=Modified; IM=Heavily Modified.

\section{Physical-chemical characterization of formulations}

Macroscopic evaluation: The homogeneity of the formulations were observed after 24 hours of preparation, identifying possible instability processes such as cream, flocculation and/or coalescence. It was also take pictures of nanoemulsion using an inversion light illumination and in different agitation time.

Microscopic evaluation: The distribution and morphology of the globules of macroscopically more stable formulations were subjected to optical microscopy with and without polarized light (Olympus ${ }^{\circledR}$ BX 50 Microscope).

pH value determination: With the aid of a digital $\mathrm{pH}$ meter ( $\mathrm{PG}$ $1800-G^{-}$haka $^{\circledR}$ ), determination was made by inserting the electrode directly into the sample at a temperature of $25 \pm 2{ }^{\circ} \mathrm{C}$.

\section{Electrical conductivity determination}

The electrical conductivity was determined at $25 \pm 2^{\circ} \mathrm{C}$ by insertion of the conductivity electrode (DM 32-Digimed ${ }^{\circledR}$ ) directly into the sample [17].

\section{Particle size and polydispersity index determination}

It was determined by laser diffraction in Beckman Coulter ${ }^{\circledR}$ LS 13 320 equipment and by dynamic light scattering in Zetasizer NanoS Malvern equipment. The readings were performed at $25 \pm 2^{\circ} \mathrm{C}$ after dilution of the samples in purified water in the proportion of 1:10. Particle size results are expressed in terms of the hydrodynamic diameter (Z-average).

\section{Multiple light scattering analysis}

The samples were followed for 24 hours with consecutive readings every 1 hour in Turbiscan ${ }^{\circledR}$ Lab Expert-Formulation, France. The system temperature was maintained at $25 \pm 2^{\circ} \mathrm{C}$. 
Citation: Maruno M (2017) Characterization and Stability Studies on Vegetable Nanoemulsions Obtained by Low Energy Process. J Nanomedic Nanotechnol S8: 003. doi:10.4172/2157-7439.S8-003

\section{Accelerated stability test}

The formulations were submitted to different values of storage temperature $\left(5 \pm 2^{\circ} \mathrm{C}, 25 \pm 2^{\circ} \mathrm{C}, 40 \pm 2^{\circ} \mathrm{C}\right.$ ) for a period of 90 days (Brazil, 2004). Subsequently, the formulations were evaluated for macroscopic and microscopic appearance, $\mathrm{pH}$ value, electrical conductivity and size of globules on the $1^{\text {st }}, 7^{\text {th }}, 15^{\text {th }}, 30^{\text {th }}, 60^{\text {th }}$ and $90^{\text {th }}$ days after the preparation.

\section{Results and Discussion}

\section{Study of the HLB required value for baru oil}

Two classical surfactants Polysorbate 80 and Sorbitan oleate were chosen to find the HLB value for baru oil and a wide range of HLB values was tested in two steps (Figure 1). The results for baru oil required HLB value show a stability range between values 6.0 to 7.0 in step I and between 6.0 and 6.25 in step II.

The results showed that baru oil exhibits an HLB value near 6.25. After HLB determination, others surfactant pair were investigated.

Choice of surfactants: For the development of the nanoemulsified system, the surfactant Sorbitan oleate was associated with other surfactants derived from castor oil having different degrees of ethoxylation. It was concluded that only the use of PEG15 castor oil allows the obtaining of a macroscopically stable nanoemulsified system after the centrifugation test. Similar results were found by Maruno [19] in which the use of this surfactant allowed to obtain a stable nanoemulsified system containing different vegetable oils.

Ternary diagram: As shown in Figure 2, the region around point 36 of the ternary diagram was explored at $5.0 \% \mathrm{w} / \mathrm{w}$ and $2.5 \% \mathrm{w} / \mathrm{w}$ concentration intervals in order to obtain a nanoemulsified system. From 10 formulations point 36 included we have 5 unstable systems tree unstable systems after centrifugation test and only two formulations were selected after the centrifugation test, they were:

1-85.0\% purified water: $5.0 \%$ baru oil: $10.0 \%$ PEG 15 castor oil

5-90.0\% purified water: 5.0\% baru oil: 5.0\% PEG 15 castor oil.

From these results and to obtain formulations with higher oil content, four new formulations were developed so that the oil: surfactant ratio was the highest possible, as shown in Table 1.

Formulations 1.a and 1.b remained stable after the centrifugation test. However, formulation 1.b presented with globules of variable sizes, observed under the optical microscope, which discarded the possibility of being a nanoemulsion system.

\section{Preliminary stability assessment}

Formulation la was subjected to the macroscopic, microscopic and centrifugation evaluation tests and then to the thermal stress test [20] and after 24 hours of preparation were evaluated for $\mathrm{pH}$, conductivity electric, particle size and evaluated by multiple light scattering technique. The results are shown in Table 2 and formulation 1a (Figures 3 and 4) was chosen for subsequent studies.

The technique of evaluation of the stability by multiple light scattering is considered an important tool in the evaluation of emulsified systems, since it allows predicting phenomena of instability such as sedimentation, cremation, flocculation and coalescence in a short period of time. Modifications along the backscattering chart are related to the phenomena of flocculation or coalescence. Thus, as shown in Figure 5, it is suggested that at untill this step the nanoemulsion system under study, will show changes in particle size during the storage period, which suggests that it is unstable and unsuitable for the proposed objectives [21].

From this result, new formulations containing the pair of surfactants Sorbitan oleate and PEG-15 castor oil were developed (Figure 6) with the addition of a cosurfactant (PEG-40 castor oil HLB value=13.0).

As shown in Figure 6, point 36 and the region around it (4 points A, B, E, F) was studied in order to improve the developed nanoemulsion system. All formulations, except for Formulation A, remained stable after 24 hours of preparation, but showed signs of instability after the centrifugation test.

\begin{tabular}{|c|c|c|}
\hline Formulas & Oil (\%w/w) & Surfactants $(\% \mathbf{w} / \mathbf{w})$ \\
\hline 1.a & 6 & 9 \\
\hline 1.b & 7 & 8 \\
\hline 1.c & 8 & 7 \\
\hline 1.d & 9 & 6 \\
\hline
\end{tabular}

Table 1: Formulations around the point 36 of the ternary diagram.

\begin{tabular}{|c|c|}
\hline \multicolumn{2}{|c|}{ Nanoemulsions (24 hours) } \\
\hline $\mathrm{pH}$ value & $5.66 \pm 0.01$ \\
\hline Electrical conductivity $(\mu \mathrm{s} / \mathrm{cm})$ & $47.23 \pm 2.94$ \\
\hline Particle size $(\mathrm{nm})$ & $85.90 \pm 1.61$ \\
\hline Polidispersity índex $(\mathrm{Pdl})$ & $0.188 \pm 0.01$ \\
\hline
\end{tabular}

Note: results expressed as mean $\pm \operatorname{SD}(n=3)$.

Table 2: Preliminary stability test - physicochemical characterization.

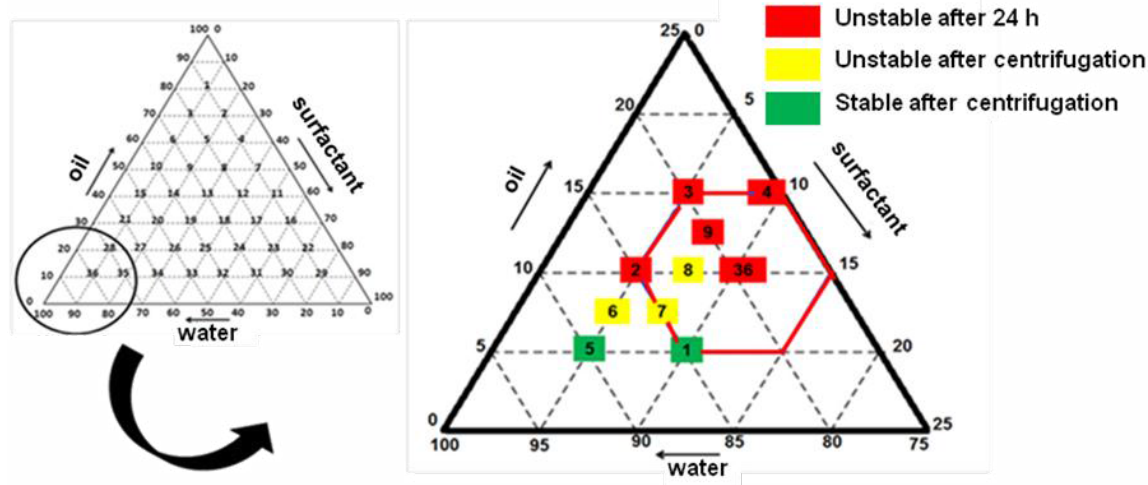

Figure 2: Ternary diagram - nanoemulsified system. 


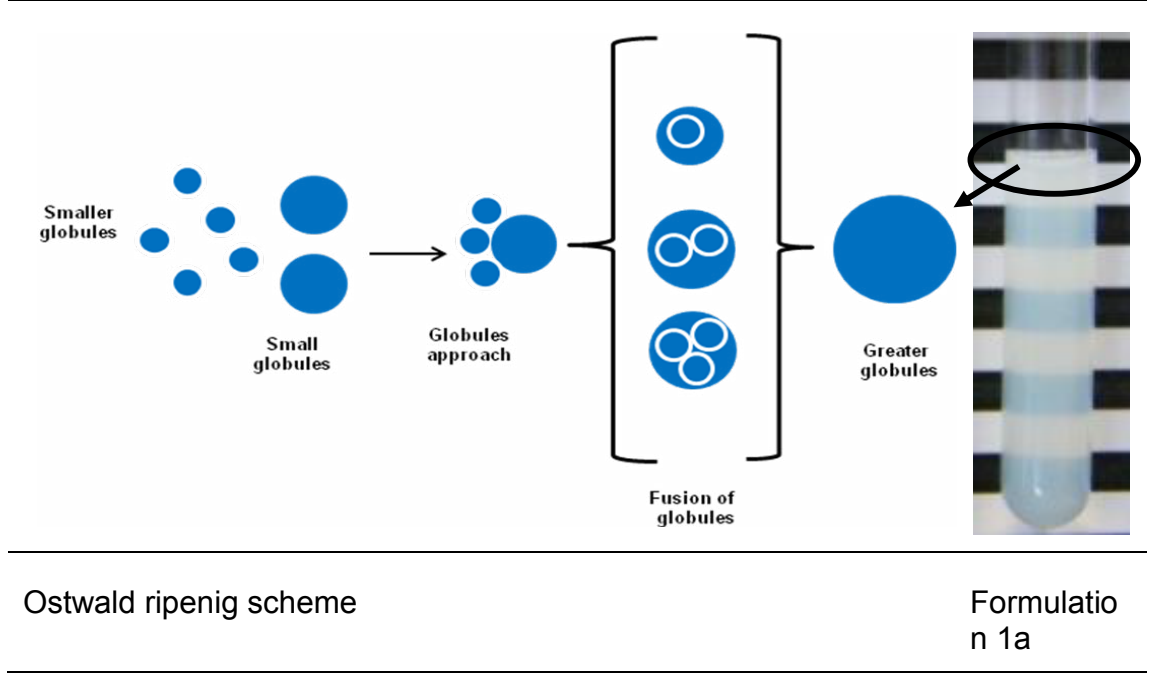

Figure 3: Formulation 1a.

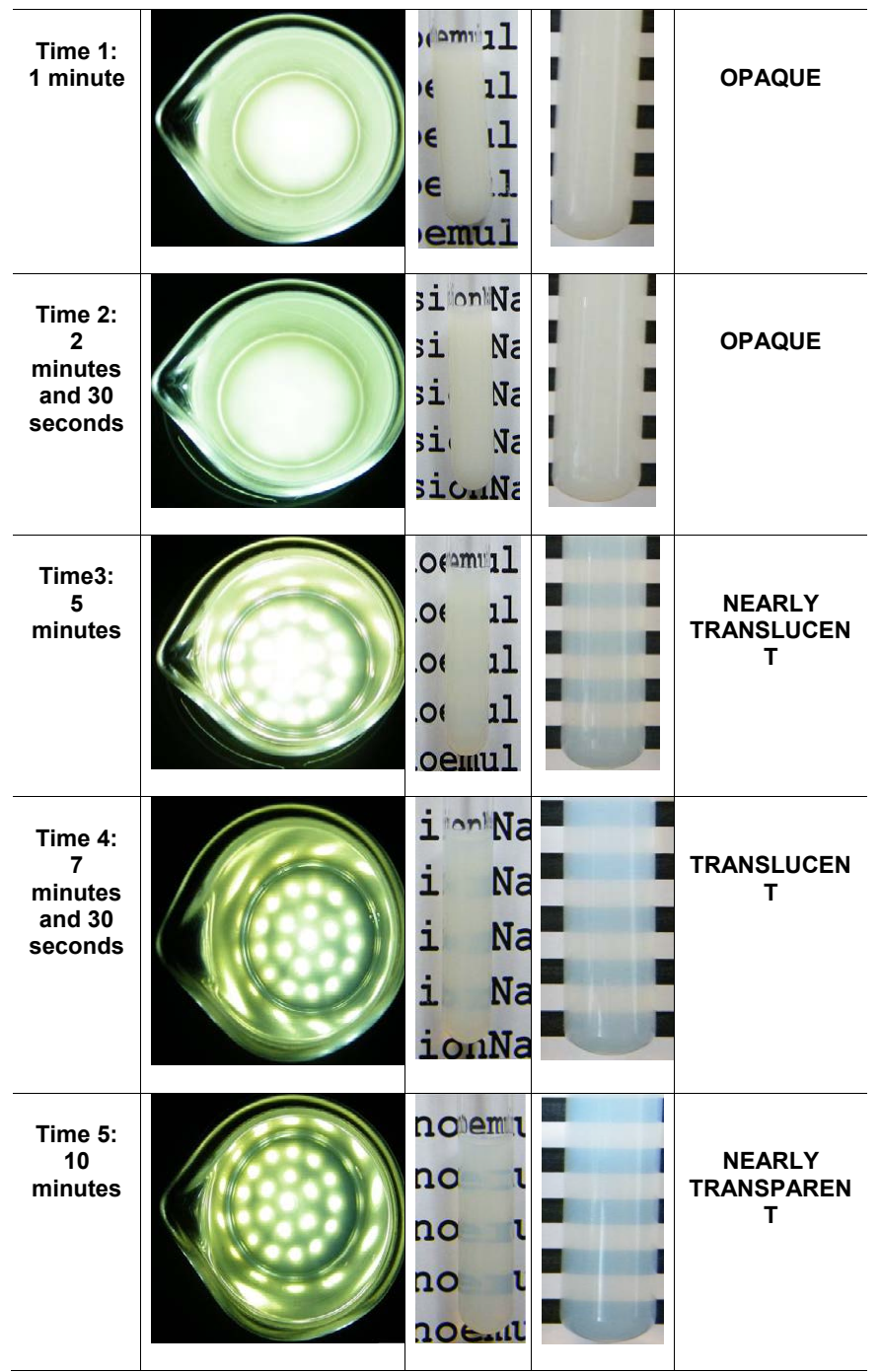

Figure 4: Macroscopic analysis of formulation 1a at different agitation time. 
Citation: Maruno M (2017) Characterization and Stability Studies on Vegetable Nanoemulsions Obtained by Low Energy Process. J Nanomedic Nanotechnol S8: 003. doi:10.4172/2157-7439.S8-003
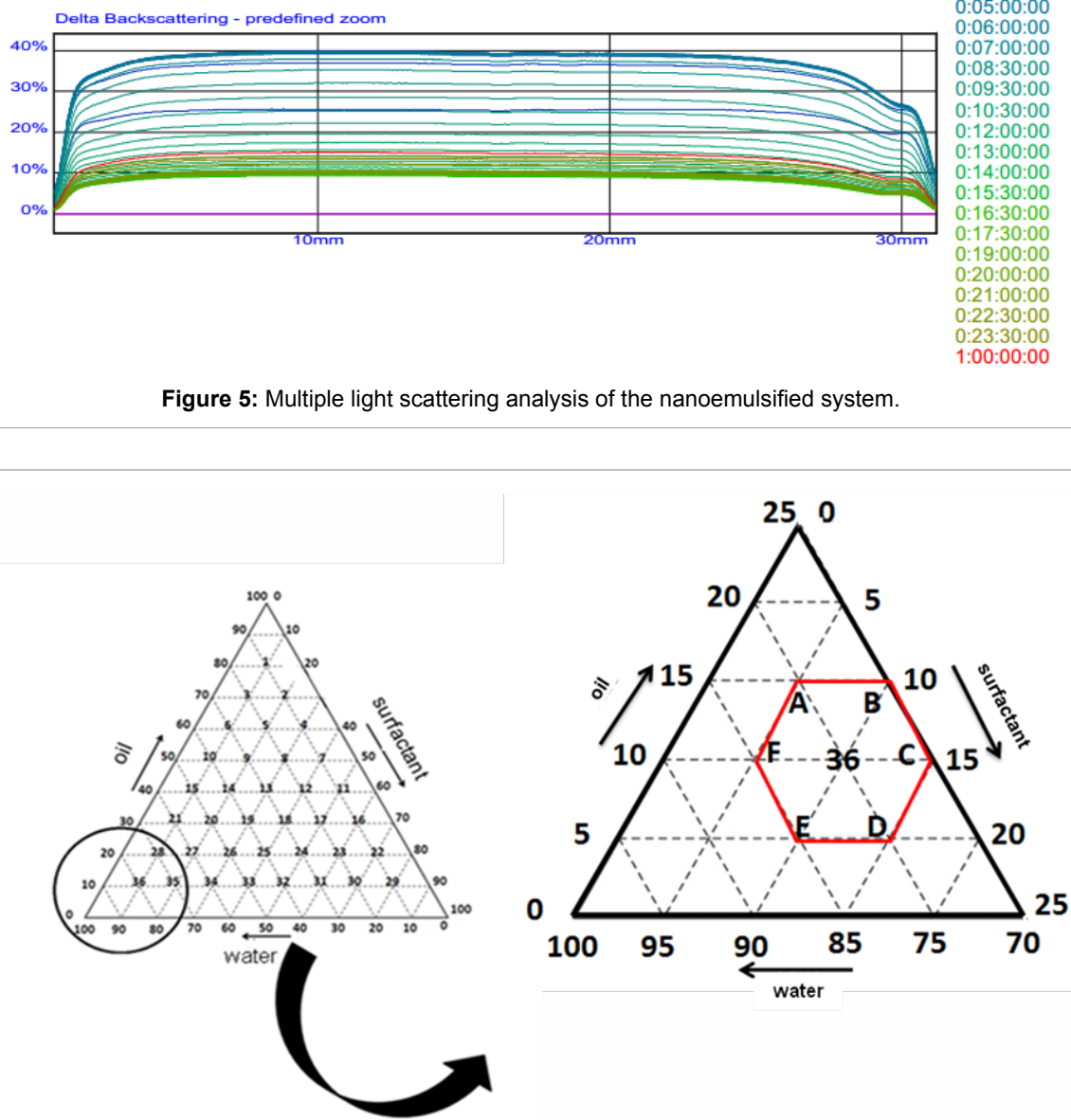

Figure 6: Ternary diagram - nanoemulsified system (PEG-15 castor oil+Sorbitan oleate).

According to the oil: surfactant ratio (10O: $5 \mathrm{~S}$ ) the formulation named as $\mathrm{F}$ was chosen and it was added with $2.0 \%$ co-surfactant. Thus, the final formulation HLB value would be 8.2 value very close to the HLB value of the surfactant PEG-15 castor oil (HLB=8.3).

As shown in Figure 7, the added cosurfactant formulation presented better profile in the evaluation by the light scattering technique, being, therefore, the one chosen for the tests of accelerated stability.

\section{Stability tests}

As shown in Table 3, formulations stored at $5 \pm 2^{\circ} \mathrm{C}$ did not show significant variation in any of the evaluated parameters suggesting that this should be the ideal storage condition for nanoemulsion. The formulations stored at temperatures of 25 and $40 \pm 2^{\circ} \mathrm{C}$ varied from 30 and 7 days, respectively. In the storage conditions at $25 \pm 2{ }^{\circ} \mathrm{C}$, the formulations showed significant variation in $\mathrm{pH}$ and electrical conductivity values while the particle size remained unchanged after the entire storage period-90 days. The detected alterations can be justified by a possible chemical instability due to degradation of formulation compounds caused by hydrolysis of the oil, or even greater solubility of specific components of the oil in the continuous phase of the emulsified system.
Under high temperature storage conditions $\left(40 \pm 2^{\circ} \mathrm{C}\right)$, the nanoemulsion system may be considered unstable because on the $7^{\text {th }}$ day of the study, significant variations were detected in the following physicochemical characteristics: $\mathrm{pH}$ and electrical conductivity. The macroscopic aspect of the formulations remained normal, nanoemulsion has fine appearance, translucent aspect and bluish reflect, which are in accordance with the concept of nanoemulsions, without alterations or signs of phase separation, and only from the $90^{\text {th }}$ day of analysis there was a significant difference in particle size, which results can be justified by the occurrence of the Ostwald ripening phenomenon (Figure 3). This phenomenon, common in nanoemulsions, is a process in which the larger globules grow to the detriment of the smaller ones, due to the greater solubility of the smaller globules in the continuous phase.

The smaller globules diffuse through the continuous phase and are deposited on the larger globules, which causes an increase in the average radius of the globules of the system. According to the Lifshitz-SlyozovWagner (LSW) [22] theory the Ostwald ripening rate is dependent on the solubility of the oil, therefore, the addition of a second component with less solubility in the aqueous phase would prevent the occurrence of such phenomenon. Additionally, recent studies suggest that the use of nonionic surfactants associated with amphiphilic polymers could contribute to the formation of a viscoelastic (and therefore more 
Citation: Maruno M (2017) Characterization and Stability Studies on Vegetable Nanoemulsions Obtained by Low Energy Process. J Nanomedic Nanotechnol S8: 003. doi:10.4172/2157-7439.S8-003

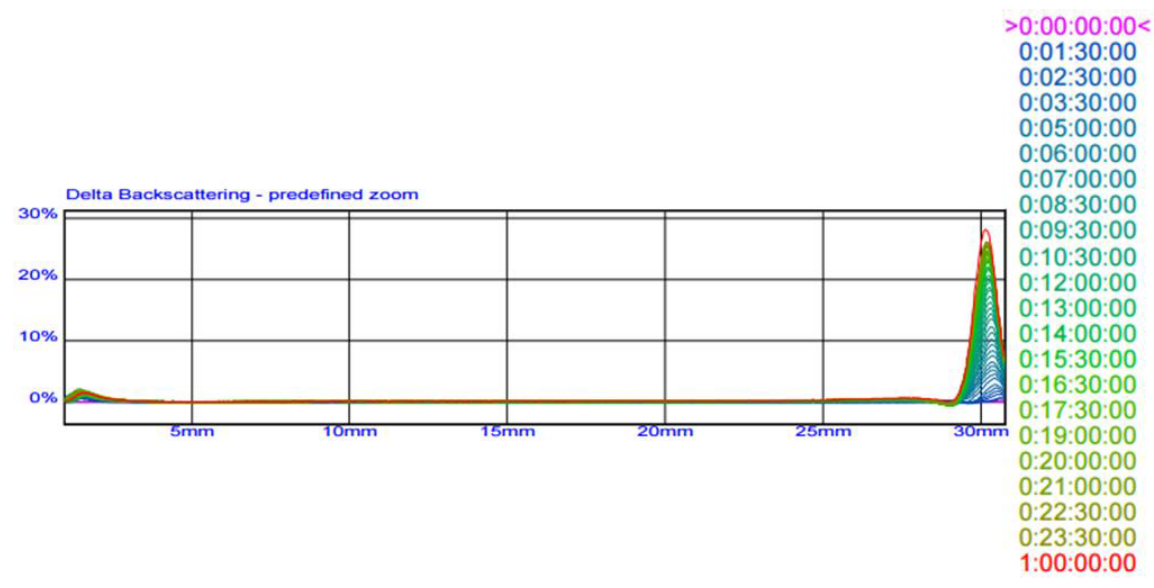

Figure 7: Multiple light scattering analysis of the added nanoemulsified system with cosurfactant.

\begin{tabular}{|c|c|c|c|c|c|c|}
\hline \multirow[b]{2}{*}{ Temperature $\left( \pm 2^{\circ} \mathrm{C}\right) \downarrow$} & \multicolumn{6}{|c|}{ Time (days) } \\
\hline & 1 & 7 & 15 & 30 & 60 & 90 \\
\hline \multicolumn{7}{|l|}{5} \\
\hline $\mathrm{pH}$ value & $4.97 \pm 0.07$ & $4.99 \pm 0.05$ & $4.97 \pm 0.02$ & $4.99 \pm 0.03$ & $4.97 \pm 0.01$ & $4.98 \pm 0.02$ \\
\hline Electrical conductivity $(\mu \mathrm{s} / \mathrm{cm})$ & $70.91 \pm 0.47$ & $71.43 \pm 0.89$ & $69.06 \pm 0.50$ & $71.05 \pm 0.36$ & $70.24 \pm 0.68$ & $71.10 \pm 0.65$ \\
\hline Particle size $(\mathrm{nm})$ & $106.95 \pm 0.92$ & $103.30 \pm 3.68$ & $106.20 \pm 3.25$ & $108.85 \pm 0.78$ & $93.71 \pm 2.57^{a}$ & $107.35 \pm 0.92$ \\
\hline Polidispersion índex & $0.233 \pm 0.03$ & $0.243 \pm 0.01$ & $0.225 \pm .06$ & $0.251 \pm 0.05$ & $0.240 \pm 0.00$ & $0.188 \pm 0.00$ \\
\hline \multicolumn{7}{|l|}{25} \\
\hline $\mathrm{pH}$ value & $4.95 \pm 0.05$ & $4.90 \pm 0.13$ & $4.92 \pm 0.06$ & $4.71 \pm 0.10$ & $4.48 \pm 0.01^{\mathrm{a}}$ & $4.59 \pm 0.08^{\mathrm{a}}$ \\
\hline Electrical conductivity $(\mu \mathrm{s} / \mathrm{cm})$ & $70.33 \pm 2.30$ & $73.56 \pm 2.29$ & $72.45 \pm 1.91$ & $78.29 \pm 1.92^{\mathrm{a}}$ & $86.89 \pm 1.53^{\mathrm{a}}$ & $88.55 \pm 1.28^{\mathrm{a}}$ \\
\hline Particle size $(\mathrm{nm})$ & $111.45 \pm 5.44$ & $109.17 \pm 4.76$ & $111.85 \pm 3.75$ & $106.20 \pm 0.71$ & $116.25 \pm 0.64$ & $104.29 \pm 7.66$ \\
\hline Polidispersion índex & $0.188 \pm 0.01$ & $0.193 \pm 0.01$ & $0.197 \pm 0.01$ & $0.232 \pm 0.03$ & $0.233 \pm 0.04$ & $0.231 \pm 0.01$ \\
\hline \multicolumn{7}{|l|}{40} \\
\hline $\mathrm{pH}$ value & $4.90 \pm 0.02$ & $4.61 \pm 0.17^{a}$ & $4.41 \pm 0.08^{\mathrm{a}}$ & $3.98 \pm 0.02^{\mathrm{a}}$ & $3.46 \pm 0.06^{a}$ & $3.38 \pm 0.04^{a}$ \\
\hline Electrical conductivity $(\mu \mathrm{s} / \mathrm{cm})$ & $68.66 \pm 1.35$ & $77.37 \pm 2.12^{\mathrm{a}}$ & $84.64 \pm 1.99^{a}$ & $100.11 \pm 4.69^{a}$ & $160.00 \pm 4.24^{a}$ & $198.34 \pm 2.56^{a}$ \\
\hline Particle size $(\mathrm{nm})$ & $100.67 \pm 8.39$ & $91.25 \pm 5.39$ & $95.56 \pm 5.49$ & $105.80 \pm 1.84$ & $115.80 \pm 4.81$ & $140.20 \pm 7.07^{\mathrm{a}}$ \\
\hline Polidispersion índex & $0.237 \pm 0.01$ & $0.170 \pm 0.00$ & $0.149 \pm 0.2$ & $0.200 \pm 0.02$ & $0.089 \pm 0.01^{\mathrm{a}}$ & $0.127 \pm 0.05$ \\
\hline
\end{tabular}

Note: Results expressed as mean \pm SD $(n=3)$. There was a significant difference between the superscript values found ( $<<0.05)$ when compared to the results of 24 hou analyzes.

Table 3: Accelerated stability test - added nanoemulsified system of cosurfactant

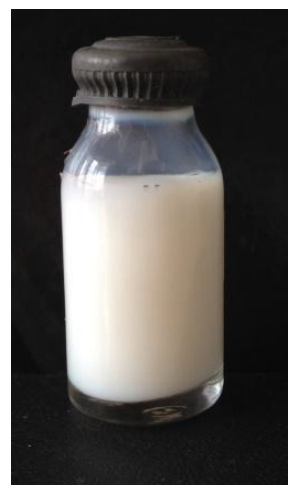

Figure 8: Photo of added nanoemulsified co-surfactant (PEG-40 castor oil) system

resistant) interfacial film at the oil/water interface and thus prevent the occurrence of this phenomenon. Such strategy can be used in later studies to improve this nanoemulsified system (Figures 8 and 9) [17,23-27].

\section{Conclusions}

Slowly increasing the water volume fraction (without surfactant) allows obtaining $\mathrm{O} / \mathrm{W}$ nanoemulsions from water in oil emulsions by phase inversion emulsification. Quantitative composition variables were optimized to minimize droplet size and polydispersity index. It was found that addition of the continuous phase to the dispersed phase resulted in the formation of oil droplets with diameters of 100-150 nm. The developed system may be a good alternative skin-care delivery 
Citation: Maruno M (2017) Characterization and Stability Studies on Vegetable Nanoemulsions Obtained by Low Energy Process. J Nanomedic Nanotechnol S8: 003. doi:10.4172/2157-7439.S8-003

Page 7 of 8
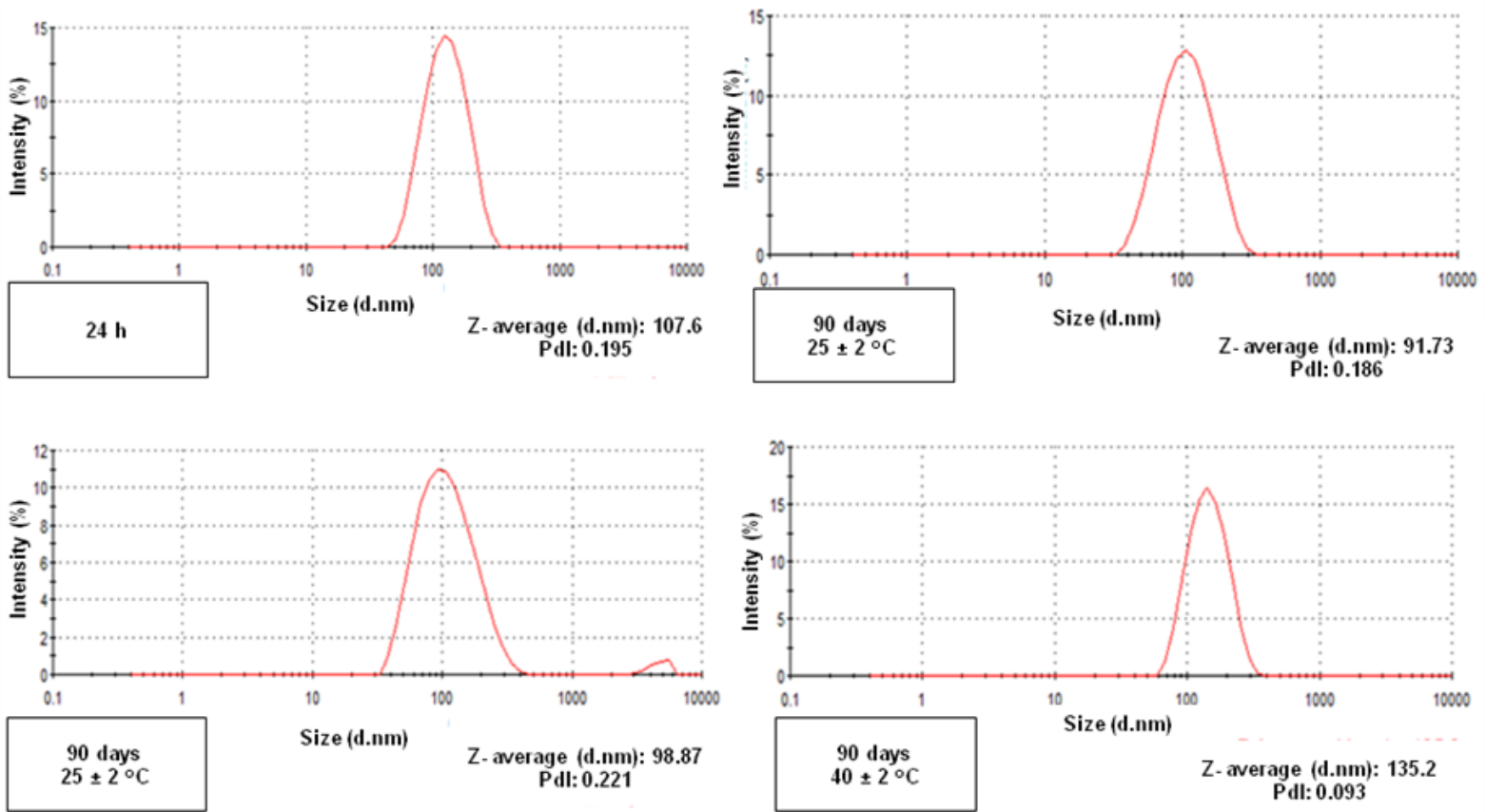

Figure 9: Particle size distribution of the nanoemulsified system added of co-surfactant after 90 days at the different storage temperatures studied.

system, particularly because the use of vegetable oil follows a global trend of using renewable resources for sustainable development in cosmetics.

\section{Acknowledgements}

This work was supported by CAPES (Coordenação de Aperfeiçoamento de Pessoal de Ensino Superior) through a student fellowship to C.S.S. Moraes

\section{References}

1. Almeida SP, Silva JA, Ribeiro JF (1991) Aproveitamento alimentar de espécies nativas dos Cerrado: araticum, baru, cagaita e jatobá. (2ndedn), Planaltina: Embrapa-Cpac.

2. Takemoto E, Okada IA, Garbelotti ML, Tavares M, Aued-Pimentel S (2001) Composição química da semente e do óleo de baru (Dipterix alata Vog.) nativo do Município de Pirenópolis, Estado de Goiás. Rev Inst Adolfo Lutz 60: 113-117.

3. Marques FG (2013) Estudo da composição química e microencapsulação do oleo fixo de Dipteryx alata Vog. Fabaceae (baru).

4. Vallilo MI, Tavares M, Aued S (1990) Composição química da polpa e da semente do fruto do cumbaru (Dipteryx alata Vog.) - caracterização do óleo da semente. Rev Inst Florestal 2: 115-125.

5. Lorenzi H (2002) Árvores brasileiras: manual de identificação e cultivo de plantas arbóreas do Brasil. 2002; 1. (4thedn), Nova Odessa: São Paulo Instituto Plantarum.

6. Drummond AL (2008) Compósitos poliméricos obtidos a partir do óleo de barusíntese e caracterização. Dissertação (Mestrado em Química) - Instituto de Química, Universidade de Brasília, Brasília.

7. Maciel-Júnior S (2010) Caracterização físico-química, qualidade e estabilidade oxidativas do óleo de Dipteryx alata Vog. (baru).

8. Tadros T, Izquierdo P, Esquena J, Solans C (2004) Formation and stability of nano-emulsions. Adv Coll Interf Sci 108-109: 303-318.

9. Morais, GG, Santos ODH, Oliveira WP, Rocha Filho PA (2008) Attainment of O/W Emulsions Containing Liquid Crystal from Annatto Oil (Bixa orellana), Coffee Oil, and Tea Tree Oil (Melaleuca alternifolia) as Oily Phase Using HLB System and Ternary Phase Diagram. J Disp Sci Techn29: 297-306.

10. Shinoda K, Saito H (1969) The Stability of O/W Type Emulsions as Functions of Temperature and the HLB of Emulsifiers: The Emulsification by PIT-method. J Coll Interf Sci 30: 258-263.
11. Salager JL, Márquez L, Pena AA, Rondón M, Silva F, et al. (2000) Current Phenomenological Know-How and Modeling of Emulsion Inversion. Ind Eng Chem Res 39: 2665-2676.

12. Sajjadi S (2006) Effect of mixing protocol on formation of fine emulsions. Chem Eng Sci 61: 3009-3017.

13. Salager JL, Forgiarini A, Márquez L, Peña A, Pizzino A, et al. (2004) Using emulsion inversion in industrial processes. Adv Coll Int Sci 108-109: 259-272.

14. Calderó G, García-Celma MJ, Solans C (2011) Formation of polymeric nanoemulsions by a low-energy method and their use for nanoparticle preparation. J Coll Int Sci 353: 406-411.

15. Wang L, Mutch KJ, Eastoe J, Heenan RK, Dong J (2009) Nanoemulsions prepared by a two-step low-energy process. Langmuir: The ACS J Surf Coll. 24: 6092- 6099 .

16. Gumiero VC (2011) Desenvolvimento e avaliação de nanoemulsões à base de óleo de babaçu (Orbignya oleifera) e extratos vegetais (Areca catechu, Glycyrrhiza glabra e Portulaca oleracea) para uso pós-sol. Ribeirão Preto.

17. Wooster TJ, Golding M, Sanguansri P (2008) Impact of oil type on nanoemulsion formation and Ostwald Ripening Stability. Langmuir 24: 12758-12765.

18. Bernardi DS, Pereira TA, Maciel NR, Bortoloto J, Vieira GS, et al. (2011) Formation and stability of oil-in-water nanoemulsions containing rice bran oil: in vitro and in vivo assessments. Journal of Nanobiotechnology 9: 44

19. Maruno M (2009) Desenvolvimento de nanoemulsões à base de óleo de gergelim aditivadas de óleo de framboesa para queimaduras da pele. Tese (Doutorado em Ciências Farmacêuticas) - Faculdade de Ciências Farmacêuticas de Ribeirão Preto, Universidade de São Paulo, Ribeirão Preto.

20. Braconi FL, Oliveira IS, Baroni MNF, Rocha Filho PA (1995) Aplicação cosmética do óleo de canola. In: XII Congresso Latino Americano e Ibérico de Químicos Cosméticos, São Paulo, ANAIS. São Paulo, Associação Brasileira de Cosmetologia, 6-19.

21. Mendes LP, Gaeti MPN, Ávila PHM, Vieira MS, Rodrigues BS, et al. (2013) Multicompartimental Nanoparticles for Co-Encapsulation and Multimodal Drug Delivery to Tumor Cells and Neovasculature. Pharm Res 31: 1106-1119.

22. Lifshitz IM, Slyozov VV (1961) The kinetics of precipitation from supersaturated solid solutions. J Phys Chem Solids 19: 35-50.

23. Chebil A, Desbrières J, Nouvel C, Six JL, Durand A (2013) Ostwald ripening of nanoemulsions stopped by combined interfacial adsorptions of molecular and macromolecular nonionic stabilizers. Coll Surf A: Phys Eng Asp 425: 24-30. 
Citation: Maruno M (2017) Characterization and Stability Studies on Vegetable Nanoemulsions Obtained by Low Energy Process. J Nanomedic Nanotechnol S8: 003. doi:10.4172/2157-7439.S8-003

Page 8 of 8

24. Garlindo-Alvarez J, Le KA, Sadtler V, Marchal P, Perrin P, et al. (2011) Enhanced stability of nanoemulsions using mixtures of nonionic surfactant and amphiphilic polyelectrolyte. Coll Surf A: Phys Eng Asp 389: 237-245.

25. Galindo-Alvarez J, Sadtler V, Marchal P, Perrin P, Tribet C, et al. (2012) Nanoemulsions with enhanced temperature stability using thermo-sensitive association of nonionic surfactant and amphiphilic polyelectrolytes. Coll Surf A Phys Eng Asp 396: 115-121.

26. Madras G, McCoy B (2013) Continuous distribution theory for Ostwald ripening comparison with the LSW approach. Chem Eng Sci 58: 2903-2909.

27. Brasil (2004) Agência Nacional de Vigilância Sanitária. Guia de estabilidade de produtos cosméticos. Séries Temáticas Série Qualidade Brasília DF. 